\title{
EVALUATION OF COLOUR CHANGE DUE TO STAINING OF BLEACHED ENAMEL TREATED WITH DIFFERENT REMINERALIZING AGENTS
}

\author{
Yasmin E Elsaid ${ }^{\prime} B D S, M S c$, Ahmed Y Ashour ${ }^{2} M S c, P h D$, Wegdan M Abd El-fattah ${ }^{3} M S c, P h D$
}

\begin{abstract}
ABSRACT
INTRODUCTION: Bleached teeth are more susceptible to stain absorption due to increased surface roughness. to various remineralizing agents. color analysis at different periods. Data were collected and statistically analyzed using ANOVA and paired t-test $(p<0.05)$. the the $1^{\text {st }}$ and $3^{\text {rd }}$ staining cycles, respectively, which was significantly lower than that of the other groups spectrophotometer.

\footnotetext{
1- Assisstant lecturer of conservative dentistry, Faculty of Dentistry, Damanhour university, Albehera, Egypt

2- Professor of Conservative Dentistry, Faculty of Dentistry, Alexandria University, Alexandria, Egypt.

3- Professor of Conservative Dentistry, Faculty of Dentistry, Alexandria University, Alexandria, Egypt.
}

OBJECTIVES: The objective of this study was to evaluate the tea stain absorption on freshly bleached enamel surface after being subjected

MATERIALS AND METHODS: Forty extracted human permanent maxillary central incisors were subjected to bleaching with $15 \%$ carbamide peroxide for 3 weeks. The teeth were then divided into four groups of 10 teeth each, according to the remineralizing agent used: [Group I: control group, which was not subjected to any remineralizing agent, Group II: acidulated phosphate fluoride (APF), Group III: casein phosphopeptide amorphous calcim phosphate (CPP-ACP) and Group IV: nano carbonate apatite (n-CAP)]. Remineralization was performed for 5 minutes daily for 1 week followed by immersion in tea solution for 10 minutes for 3 consecutive days. Spectrophotometer was used for

RESULTS: After bleaching, the $\mathrm{n}$-CAP group showed the least total color change $(\Delta \mathrm{E})$ with a mean of $(5.13 \pm 1.40)$ and $(7.85 \pm 2.21)$ after

CONCLUSION: The reduction of tea stains absorption after bleaching varies according to the type of the remineralizing agents used.

KEYWORDS: Bleaching; fluoride, casein phosphopeptide - amorphous calcium phosphate, nano- carbonate apatite, stain absorption,

\section{INTRODUCTION}

The active products of vital tooth bleaching such as carbamide and hydrogen peroxide are the most commonly used agents for different bleaching modalities, which vary according to peroxide concentration, mode of application and time of exposure(1).

The whitening products available for vital tooth bleaching can be applied on tooth surface at the office by the dentist or at home by the patient, under the dentist's supervision. In-office bleaching generally uses relatively high level of hydrogen peroxide (HP) for shorter periods. Home bleaching typically uses a relatively low level of hydrogen peroxide or carbamide peroxide (CP) at night for at least 2 weeks(2).

The only concentration that so far received the seal of acceptance by American Dental Association (ADA) was the $10 \pm 1 \%$ carbamide peroxide, which assures its safety and efficacy for at home tooth bleaching with custom tray(3). However, the dentist-prescribed home-applied technique most commonly uses a $10 \%$ or $15 \%$ carbamide peroxide gel (4).

Bleaching works by the oxidation of polymeric organic substances (pigments) that cause tooth discoloration. The free radicals generated from $\mathrm{H}_{2} \mathrm{O}_{2}$ disrupt the double bonds of the organic pigments, thereby altering the pigments into achromic low-molecular substances(5). Oxidative action not only oxidizes the pigmented materials of the teeth but also affects the organic matter of the teeth (6).

Although no macroscopically, clinically remarkable damages because of vital bleaching of the dental hard tissues have been described in literature, there are scientific reports which demonstrate alterations of the histological aspects and composition of bleached dental enamel (7). A clinical implication of these finding may be that bleached teeth are more susceptible to extrinsic discoloration due to increased surface roughness (8).

For these reasons, it is essential that the damaged enamel surface should be recovered after bleaching for a lasting bleaching effect. Previous studies have reported that fluoride or casein phosphopeptide-amorphous calcium phosphate (CPP-ACP) recovered the damaged enamel surface and prevented staining (7).

Recently, the application of hydroxyapatite (HAP) to the biomimetic repair of damaged enamel directly has attracted considerable great attention in dental research because of its chemical and structural similarity to tooth minerals. Moreover, HAP can have new physical properties if it can be made similar to the enamel crystal size by nano technology (9).

On the other hand, the apatite structure of bone or tooth is not technically pure apatite due to the element replaced in the lattice structure. Bone mineral contains a substantial amount of carbonate (5-8 wt.\%) in the human body. Therefore, carbonate apatite $\left(\mathrm{CAP}, \mathrm{Ca}_{10}\left(\mathrm{PO}_{4} \mathrm{CO}_{3}\right)_{6}(\mathrm{OH})_{2}\right)$ is more suitable for remineralization than HAP (9).

Therefore, this study was designed to evaluate the effect of different remineralizing agents to minimize stains absorption of freshly bleached enamel surface and hence, maintain the effect of bleaching procedure for longer time.

\section{MATERIALS AND METHODS}

\section{1) Teeth selection}

Forty extracted human permanent maxillary central incisors, extracted for periodontal reasons, were selected for this study. Teeth with cracks, caries or restorations were excluded. Calculus and stains were removed with hand scaler, rubber cup \& polishing paste. Each tooth was numbered on root portion, and then all teeth were stored in 
normal saline at room temperature from the day of extraction until the test was done.

\section{2) Bleaching procedure}

- For bleaching of the samples, all teeth samples were placed in Petri dish using sticky wax to stabilize them in place, and the labial surfaces of the crowns were then single coated with Opalescence 15\% PF (Ultradent Products, inc, South Jordan, UT, USA) using a brush. This was left in place for 2 hours, according to the manufacturer's instructions. After which, the specimens were fully cleaned under running water then the samples were stored in artificial saliva for the next 22 hours.

- This bleaching-storage cycle was repeated daily for 3 consecutive weeks during which artificial saliva was daily changed and used for storage of the teeth after bleaching.

After the last bleaching-storage cycle, colour evaluation of all teeth was done using spectrophotometer (VITA Easyshade Compact, VITA Zahnfabrik, Bad Säckingen, Germany) and used as baseline data.

- In order to standardize the location of the probe tip application, a groove of $1 / 2 \mathrm{~mm}$ depth was prepared 1-2 $\mathrm{mm}$ away from the incisal edge using rose head bur.

\section{3) Grouping}

After 3 weeks of bleaching, all 40 teeth samples were divided into four groups of ten teeth each, according to the type of the remineralizing agent used.

Group I: Samples were stored only in artificial saliva without surface treatment. (Control group)

Group II: Remineralized using thixotropic acidulated phosphsate fluoride treatment gel $1.23 \%$. Gelato APF (Deepak Products,inc, USA. )

Group III: Remineralized using casein phosphopeptide amorphous calcium phosphate GC Tooth mousse (GC Corp., Tokyo, Japan)

Group IV: Remineralized using nano-carbonate apatite Dentiguard sensitive (Daewoong pharmaceutical Co, LTD, Korea)

For group II, III, and IV, the remineralizing agents were applied on dried labial surface of their crowns using a brush and left for five minutes according to the manufacturer's instructions. After which, the remineralizing agent over the enamel surface was gently wiped off with gauze and the teeth samples were stored in artificial saliva until the next day. This remineralization procedure was repeated for 7 successive days (9).

\section{4) Immersion in staining solution}

After 7 days of remineralization, all the groups were removed from the artificial saliva and the root apices were sealed with cyanoacrylate to avoid stain penetration through the root canals, then all teeth were immersed in freshly prepared tea solution for 10 minutes. This staining procedure was repeated for 3 successive days. Colour evaluation was done after the first and third staining cycles. Each day, fresh tea solution was prepared for the study by boiling two grams of tea in $100 \mathrm{ml}$. of distilled water for 5 minutes (7).

\section{5) Colour evaluation}

The labial surfaces of the crowns of all the samples were analyzed under the spectrophotometer against a white background(10) at the following stages in the study:

1- After the last bleaching-storage cycle (baseline).

2 - After the $1^{\text {st }}$ staining cycle.

3 - After the $3^{\text {rd }}$ staining cycle.
Before each specimen measurement, VITA Easyshade was calibrated, and then the fiber optic probe of the spectrophotometer was applied perpendicular on the middle third of the labial surface.

For all stages, the color of each specimen was recorded in CIELAB color system in the form of $\mathrm{L}^{*}, \mathrm{a}^{*}$, and $\mathrm{b}^{*}$ with the spectrophotometer where:

$\mathrm{L}^{*}$ characterizes the lightness and can range between 0 (dark) to 100 (light).

$a^{*}$ defines a color on a red - green axis.

$b^{*}$ defines a color on a yellow - blue axis (9).

The colour measurement was done twice and the average value was obtained. The overall colour difference $\Delta \mathrm{E}^{*}$ from the three measurements was calculated using Hunter's equation:

$\Delta \mathrm{E}^{*}=\left[(\Delta \mathrm{L} *)^{2}+\left(\Delta \mathrm{a}^{*}\right)^{2}+\left(\Delta \mathrm{b}^{*}\right)^{2}\right]^{1 / 2}$

Where $\Delta \mathrm{L}^{*}, \Delta \mathrm{a}^{*}$, and $\Delta \mathrm{b}^{*}$ represent the difference in $\mathrm{L}^{*}$, $\mathrm{a}^{*}$, and $\mathrm{b}^{*}$ values, respectively.

\section{STATISTICL ANAL YSIS}

Data were fed to the computer and analyzed using IBM SPSS software package version 20.0 (11-12). For normally distributed data, comparison between more than two populations was analyzed using F-test (ANOVA), and followed by Post Hoc test (Scheffe) for pairwise comparison between groups. Paired t-test was used to analyse two paired data. Significance of the obtained results was judged at the $5 \%$ level.

\section{RESULTS}

Total colour change $\left(\Delta \mathrm{E}^{*}\right)$ of all groups after $1^{\text {st }}$ and $3^{\text {rd }}$ staining cycles was analyzed using ANOVA test, where the measurement after bleaching was used as the baseline. After the $1^{\text {st }}$ and the $3^{\text {rd }}$ staining cycles, the results revealed that n-CAP group showed the least mean color change from baseline, as indicated by $\Delta \mathrm{E}^{*}(5.13 \pm 1.40)$ and $(7.85 \pm 2.21)$ respectively, compared to all other groups. The difference between the four groups was statistically significant with $\mathrm{p}<$ 0.001 after the $1^{\text {st }}$ and the $3^{\text {rd }}$ staining cycles.

Pairwise comparison between the four groups after the 1 st staining cycle revealed that the difference was statistically significant between (n-CAP and control group) and (n-CAP and APF) with P1 $<0.001$ and $\mathrm{P} 2=0.001$, respectively, and the least significant difference was between ( $\mathrm{n}$-CAP and CPP-ACP) with $\mathrm{p}=0.006$, while the difference between all the other groups was statistically nonsignificant.

Pairwise comparison between the four groups after the 3rd staining cycle showed that there was a statistically significant difference between (n- CAP and control), (n$\mathrm{CAP}$ and APF) and (n-CAP and CPP-ACP) with p1 $=0.012$, $\mathrm{p} 2<0.001$ and $\mathrm{p} 3=0.012$, respectively. The difference between (CPP-ACP and APF) was statistically significant with $\mathrm{p} 2<0.01$, while the difference between all the other groups was statistically non significant. (Table 1, figure 1,2) 
Table (1): Comparison between different remineralizing agents according to $\Delta \mathrm{E}$ after $1^{\text {st }}$ and $3^{\text {rd }}$ staining cycles.

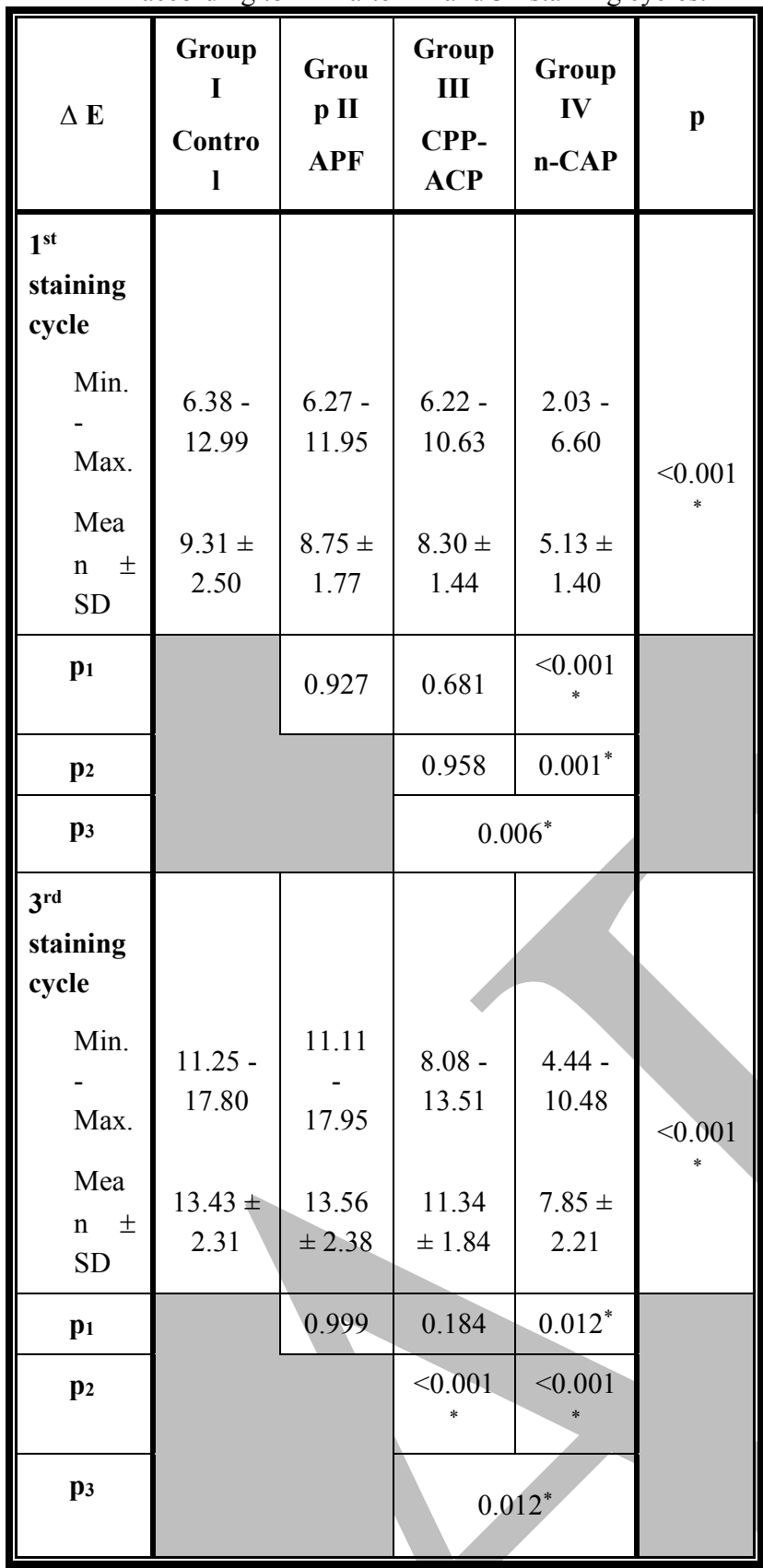

$\mathrm{p}$ : $\mathrm{p}$ value for F test (ANOVA) for comparing between the different studied groups

$\mathrm{p}_{1}: \mathrm{p}$ value for Post Hoc test (Scheffe) for comparing between control with each other material

$\mathrm{p}_{2}: \mathrm{p}$ value for Post Hoc test (Scheffe) for comparing between APF with CPP-ACP and n-CAP

$\mathrm{p}_{3}: \mathrm{p}$ value for Post Hoc test (Scheffe) for comparing between

CPP-ACP and n-CAP

*: Statistically significant at $\mathrm{p} \leq 0.05$

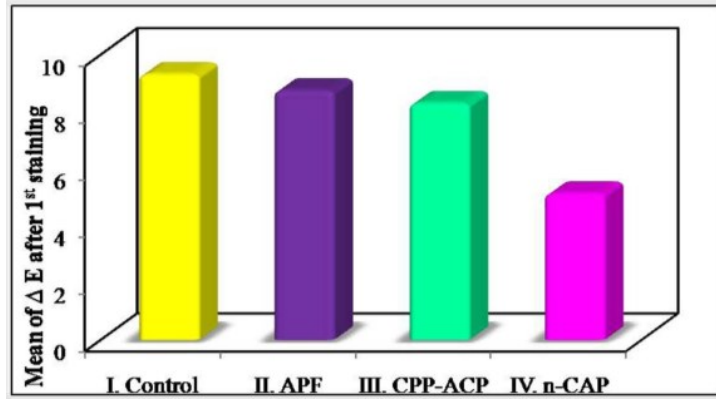

Figure 1: Mean $\Delta \mathrm{E}$ of the different groups after the $1^{\text {st }}$ staining cycle.

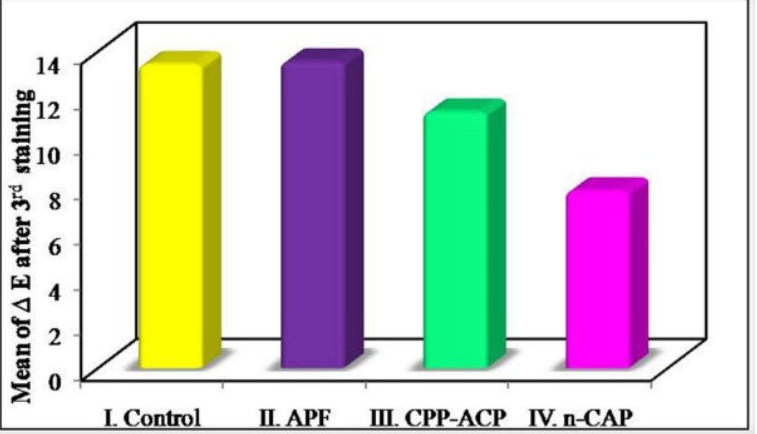

Figure 2: Mean $\Delta \mathrm{E}$ of the different groups after the $3^{\text {rd }}$ staining cycle.

The paired $t$ - test was used for comparison between $\Delta \mathrm{E}$ after the $1^{\text {st }}$ and $3^{\text {rd }}$ staining cycles for each material. There was a statistically significant difference between the $1^{\text {st }}$ an $3^{\text {rd }}$ staining cycles for all the groups, with the least significant difference in the n-CAP group $(p=0.003)$. (Table2, figure3)

Table (2): Comparison between different staining cycles according to $\Delta \mathrm{E}$ for each remineralizing agent.

\begin{tabular}{|c|c|c|c|}
\hline$\Delta \mathbf{E}$ & $\begin{array}{c}1^{\text {st }} \text { staining } \\
\text { cycle }\end{array}$ & $\begin{array}{c}3^{\text {rd }} \text { staining } \\
\text { cycle }\end{array}$ & p \\
\hline $\begin{array}{l}\text { I. Control } \\
\text { Min. - Max. } \\
\text { Mean } \pm \text { SD }\end{array}$ & $\begin{array}{l}6.38-12.99 \\
9.31 \pm 2.50\end{array}$ & $\begin{array}{c}11.25- \\
17.80 \\
13.43 \pm 2.31\end{array}$ & $<0.001^{*}$ \\
\hline $\begin{array}{l}\text { II. APF } \\
\text { Min. - Max. } \\
\text { Mean } \pm \text { SD }\end{array}$ & $\begin{array}{l}6.27-11.95 \\
8.75 \pm 1.77\end{array}$ & $\begin{array}{c}11.11- \\
17.95 \\
13.56 \pm 2.38\end{array}$ & $<0.001^{*}$ \\
\hline $\begin{array}{l}\text { III. CPP-ACP } \\
\text { Min. - Max. } \\
\text { Mean } \pm \text { SD }\end{array}$ & $\begin{array}{l}6.22-10.63 \\
8.30 \pm 1.44\end{array}$ & $\begin{array}{l}8.08-13.51 \\
11.34 \pm 1.84\end{array}$ & $<0.001^{*}$ \\
\hline $\begin{array}{l}\text { IV. n-CAP } \\
\text { Min. - Max. } \\
\text { Mean } \pm \text { SD }\end{array}$ & $\begin{array}{l}2.03-6.60 \\
5.13 \pm 1.40\end{array}$ & $\begin{array}{c}4.44-10.48 \\
7.85 \pm 2.21\end{array}$ & $0.003^{*}$ \\
\hline
\end{tabular}

p: $p$ value for Paired t-test for comparing between $1^{\text {st }}$ and $3^{\text {rd }}$ staining cycle

*: Statistically significant at $\mathrm{p} \leq 0.05$

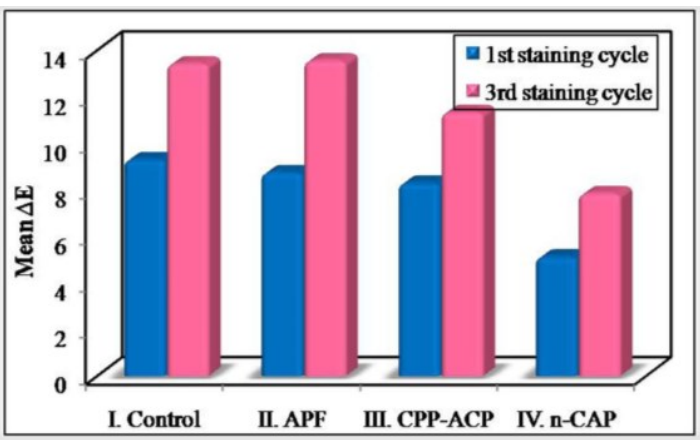

Figure 3: Comparison between different staining cycles according to $\Delta \mathrm{E}$ for each remineralizing agent 


\section{DISCUSSION}

Vital tooth bleaching with carbamide peroxide gels is becoming more and more popular. Although no macroscopically or clinically remarkable damages due to vital bleaching of the dental hard tissues have been described in literature, there are scientific reports which demonstrate alterations of the histological aspects and composition of bleached dental enamel (13).

The whitening effect of the material used in this study (Opalescence 15\% PF) is achieved by decomposition of CP into urea and $\mathrm{H}_{2} \mathrm{O}_{2}$, and the morphological changes of teeth have been attributed to these degradation by-products (14 ) and the other components of the bleaching gel such as glycerine and carbopole, which act as a demineralizing agents (15). Hence, the microstructural changes and surface roughness resulted after bleaching render the surface more liable to pigments adherence than the original unbleached surface.

The spectrometric method based on the CIE-Lab system is recognized as being a reliable and objective tool for a quantitative evaluation of the vital tooth colour change perception $(2,16)$.

Three types of remineralizing agents were used in the current study (fluoride, CPP-ACP and n-CAP) in an attempt to minimize post bleaching staining.

Teeth samples treated with n-CAP after bleaching showed the least total color change $(\triangle \mathrm{E})$ in comparison to the other three groups after the $1^{\text {st }}$ and $3^{\text {rd }}$ immersion in the tea solution. Moreover, pairwise comparison between the colour change $(\Delta \mathrm{E})$ after the $1^{\text {st }}$ and the $3^{\text {rd }}$ staining cycles for each remineralizing agent revealed that $n$-CAP group showed the least difference when compared to the other three groups. This may be attributed to the ability of the nCAP to attach to the roughened tooth surface, forming a mineral coating that can fill the pores and scratches, leading to decrease in stains absorption on the bleached enamel surface.

The ability of n-CAP to adhere and form mineral coating on the surface is confirmed in the study of Lee et al. (17), who found under SEM examination an effective coating occluding the dentinal tubules after using dentifrice containing $20 \% \mathrm{n}$-CAP. It is also confirmed with those of Roveri et al. (18), who found no changes on enamel slabs treated with fluoride after ortophosphoric acid; interprismatic and prismatic enamel structures appear still evident. On the contrary, after treatment of the enamel slabs with n-CAP the interprismatic and prismatic enamel structures appear to be completely hidden by a thick homogeneous apatitic layer.

It was found that apatite structure of bone or tooth is not pure hydroxyapatite; it contains a substantial amount of carbonate (19). Therefore, the n-CAP is known to have a much higher similarity to the inorganic component of bone or tooth structure than crystalline HAP, moreover, n-CAP has much higher solubility and reactivity (17). In addition, the nano-sized particles have a large surface area and increased proportion of atomicity and bioactive properties; therefore, they have high affinity towards the enamel surface and easily deposit and adhere on irregular spaces (9).

The results of the current study are consistent with those of Kim et al. (9), who found under spectrophotometric analysis that n-CAP treated group showed the least total colour change $(\triangle \mathrm{E})$ of stained bleached enamel when compared to other remineralizing agents (flouride, CPP-ACP and artificial saliva); their results were confirmed by SEM examination which showed needle-shaped crystals on the bleached surface treated with n-CAP and a decrease in the micropores.

According to this study, fluoride and CPP-ACP surface treatments showed a reduced total color change after the $1^{\text {st }}$ immersion in tea solution when compared to the control group samples; however, the difference was insignificant. After the $3^{\text {rd }}$ immersion in tea solution, fluoride and control groups showed the same colour change, indicating a weak effect of staining prevention, while the CPP- ACP showed reduced colour change in comparison to both of these two groups.

Fluoride ions generate a surface modification of the natural enamel apatite crystals increasing their crystallinity degree due to a partial structural conversion of hydroxyapatite into fluoride substituted hydroxyapatite resulting in increased relative mechanical and acid resistance. Products containing fluoride behave by reducing apatite dissolution rather than replacement of the lost minerals $(18,20)$.

On the other hand, other studies found that fluoride application after dental bleaching is an effective agent for reduction of demineralization and surface roughness; however, some of them used it daily after dental bleaching (21-22).

The CPP containing the amino acid cluster sequence -Ser (P)-Ser (P)-Ser (P)-Glu-Glu- has the ability under alkaline conditions to bind and stabilize calcium and phosphate in a soluble, amorphous state $(23,24)$. When CPP-ACP is applied in the oral environment, it will bind to biofilms, plaque, bacteria, hydroxyapatite and soft tissue, localizing bio available calcium and phosphate ions and maintain the high activities of the free ions through the reservoir of bound ACP. It will thus maintain a state of super saturation in close proximity to tooth enamel, reducing demineralization and enhancing remineralization. Hence, the weak protective effect of CPP-ACP in the current study may be attributed to the lack of plaque biofilm and salivary pellicle to which the CPP would adhere, since they can act as a reservoir for remineralizing agents, concentrating them near the demineralized surface (25). As a reservoir, plaque usually contains much higher concentrations of fluoride, calcium, and phosphate than saliva (26).

Unfortunately, artificial saliva cannot model demineralization and remineralization processes in the intraoral environment related to various biological factors, such as salivary pellicle and biofilm, as well as to inherent fluoride that favours the formation of protective calcium fluoride $\left(\mathrm{CaF}_{2}\right)$ layer (27).

An important component of saliva is its proteins, such as the glycoproteins which adsorb onto tooth structure to form the protective pellicle layer, and the phosphoproteins which regulate calcium saturation of the saliva. Hence, some authors suggested that, for CPP-ACP and other agents which interact extensively with saliva, it is essential to test them in models where human saliva is used, rather than with artificial saliva solutions which lack a complete repertoire of proteins, since studies which exclude salivary proteins will underestimate the true remineralizing actions of this agent $(25,28)$.

The findings of the present study are consistent with those of Kim et al. (9), who found that the re-staining prevention effect could not be confirmed by CPP-ACP, while the fluoride treated group showed slight better 
protective effect. The results of the present study are also consistent with those of $\mathrm{Li}$ et al. (29), who found that attached ACP disappeared completely from the enamel surface after the ultrasonic treatment and concluded that the affinity of ACP to enamel is extremely low.

However, these findings contradict with results of Singh et al. (7), who found that fluoride and CPP-ACP showed an effective reduction of total color change of bleached teeth after immersion in tea solution, and also contradict with those of Matias et al. (30), who found that application of CPP-ACP after microabrasion effectively reduced the surface roughness.

Hence, the null hypothesis of this study has been rejected. The colour change of the different groups due to immersion in tea solution varied with the type of the remineralizing agent used after bleaching.

\section{CONCLUSIONS}

From the results of the current study, it was concluded that:

1. Post bleaching tea staining can be reduced by using different remineralizing agents.

2. The reduction of tea stains absorption after bleaching varies according to the type of the remineralizing agents used.

3. After bleaching, the nano- carbonate apatite showed the highest effect on maintenance of colour stability and reduction of tea stains absorption in comparison to the other remineralizing agents.

4. The freshly bleached enamel surface, if not remineralized, becomes darker than the original unbleached surface upon staining.

\section{CONFLICT OF INTEREST}

The authors declare that they have no conflict of interest.

\section{REFERENCES}

1. Meireles SS, Fontes ST, Coimbra LA, Bona AD, Demarco FF. Effectiveness of different carbamide peroxide concentrations used for tooth bleaching: an in vitro study. J Appl Oral Sci. 2012; 20: 186-91.

2. Joiner A. The bleaching of teeth: a review of the literature. J Dent. 2006; 34: 412-9.

3. American dental asociation. accepted over-the-counter products [online]: available at: www.ada.org/ada/seal/shoppinglist.aspx.

4. Almas K, Al-Harbi M, Al-Gunaim M. The effect of a $10 \%$ carbamide peroxide home bleaching system on the gingival health. J Contemp Dent Pract. 2003; 4: 32-41.

5. Minoux M, Serfaty R. Vital tooth bleaching: biologic adverse effects-a review. Quintessence Int. 2008; 39: 645-59.

6. Jiang T, Ma X, Wang Y, Tong H, Shen X, Hu Y, et al. Investigation of the effects of $30 \%$ hydrogen peroxide on human tooth enamel by Raman scattering and laserinduced fluorescence. J Biomed Opt. 2008; 13: 014019.

7. Singh RD, Ram SM, Shetty O, Chand P, Yadav R. Efficacy of casein phosphopeptide-amorphous calcium phosphate to prevent stain absorption on freshly bleached enamel: An in vitro study. J Conserv Dent. 2010; 13: 76-9.
8. Dahl JE, Pallesen U. Tooth bleaching--a critical review of the biological aspects. Crit Rev Oral Biol Med. 2003; 14: 292-304.

9. Kim YS, Kwon HK, Kim BI. Effect of nano-carbonate apatite to prevent re-stain after dental bleaching in vitro. J Dent. 2011; 39: 636-42.

10. Borges AL, Costa AK, Saavedra GS, Komori PC, Borges AB, Rode SM. Color stability of composites: effect of immersion media. Acta Odontol Latinoam. 2011; 24: 193-9.

11. Kirkpatrick LA, Feeney BC. A simple guide to IBM SPSS statistics for version 20.0. Student ed. Belmont, Calif: Wadsworth, Cengage Learning; 2013: 115.

12. Leslie E, Geoffrey J, James M. Interpretation and uses of medical statistics 4th ed: Oxford Scientific Publications; 1991: 411-6.

13. McGuckin RS, Babin JF, Meyer BJ. Alterations in human enamel surface morphology following vital bleaching. J Prosthet Dent. 1992; 68: 754-60.

14. Dudea D, Florea A, Mihu C, Campeanu R, Nicola C, Benga $G$. The use of scanning electron microscopy in evaluating the effect of a bleaching agent on the enamel surface. Rom J Morphol Embryol. 2009; 50: 435-40.

15. Rodrigues JA, Marchi GM, Ambrosano GM, Heymann HO, Pimenta LA. Microhardness evaluation of in situ vital bleaching on human dental enamel using a novel study design. Dent Mater. 2005; 21: 1059-67.

16. Dietschi D, Rossier S, Krejci I. In vitro colorimetric evaluation of the efficacy of various bleaching methods and products. Quintessence Int. 2006; 37: 515-26.

17. Lee SY, Kwon HK, Kim BI. Effect of dentinal tubule occlusion by dentifrice containing nano-carbonate apatite. J Oral Rehabil. 2008; 35: 847-53.

18. Roveri N, Battistella E, Foltran I, Foresti E, Iafisco M, Lelli M, et al. Synthetic biomimetic carbonatehydroxyapatite nanocrystals for enamel remineralization. Advanced Materials Research. 2008; 47-50: 821-4.

19. Bar-Hillel R, Feuerstein O, Tickotsky N, Shapira J, Moskovitz M. Effects of amorphous calcium phosphate stabilized by casein phosphopeptides on enamel de- and remineralization in primary teeth: an in vitro study. $\mathrm{J}$ Dent Child (Chic). 2012; 79: 9-14.

20. Roveri N, Battistella E, Bianchi CL, Foltran I, Foresti E, Iafisco $M$, et al. Surface enamel remineralization: biomimetic apatite nanocrystals and fluoride ions different effects. Journal of Nanomaterials. 2009: 1-9.

21. Martin JM, de Almeida JB, Rosa EA, Soares P, Torno $\mathrm{V}$, Rached RN, et al. Effect of fluoride therapies on the surface roughness of human enamel exposed to bleaching agents. Quintessence Int. 2010; 41: 71-8.

22. Bizhang M, Seemann R, Duve G, Romhild G, Altenburger JM, Jahn KR, et al. Demineralization effects of 2 bleaching procedures on enamel surfaces with and without post-treatment fluoride application. Oper Dent. 2006; 31: 705-9. 
23. Hegde MN, Shetty S, Pardal D. Remineralization of enamel sub-surface lesion using casein phosphopeptide amorphous calcium phosphate (CPP-ACP) - a quantitative energy dispersive $\mathrm{X}$-ray analysis (EDAX). J Conserv Dent. 2007; 10: 19-25.

24. Jayarajan J, Janardhanam P, Jayakumar P. Efficacy of CPP-ACP and CPP-ACPF on enamel remineralization an in vitro study using scanning electron microscope and DIAGNOdent. Indian J Dent Res. 2011; 22: 77-82.

25. Oshiro $M$, Yamaguchi $K$, Takamizawa $T$, Inage $H$, Watanabe T, Irokawa A, et al. Effect of CPP-ACP paste on tooth mineralization: an FE-SEM study. J Oral Sci. 2007; 49: 115-20.

26. Pradeep K, Rao PK. Remineralizing agents in the noninvasive treatment of early carious lesions. Int J Dent Case Reports. 2011; 1: 73-84.

27. Wang X, Mihailova B, Klocke A, Heidrich S, Bismayer U. Effect of Artificial Saliva on the Apatite Structure of
Eroded Enamel. International Journal of Spectroscopy. $2011 ; 2011$.

28. Giulio AB, Matteo Z, Serena IP, Silvia M, Luigi C. In vitro evaluation of casein phosphopeptide-amorphous calcium phosphate (CPP-ACP) effect on stripped enamel surfaces. A SEM investigation. J Dent. 2009; 37: 228-32.

29. Li L, Pan HH, Tao H, Xu X, Mao C, Gu X, et al. Repair of enamel by using hydroxyapatite nanoparticles as the building blocks. Journal of Materials Chemistry. 2008; 18: 4079-84.

30. Mathias J, Kavitha S, Mahalaxmi S. A comparison of surface roughness after micro abrasion of enamel with and without using CPP-ACP: An in vitro study. J Conserv Dent. 2009; 12: 22-5.

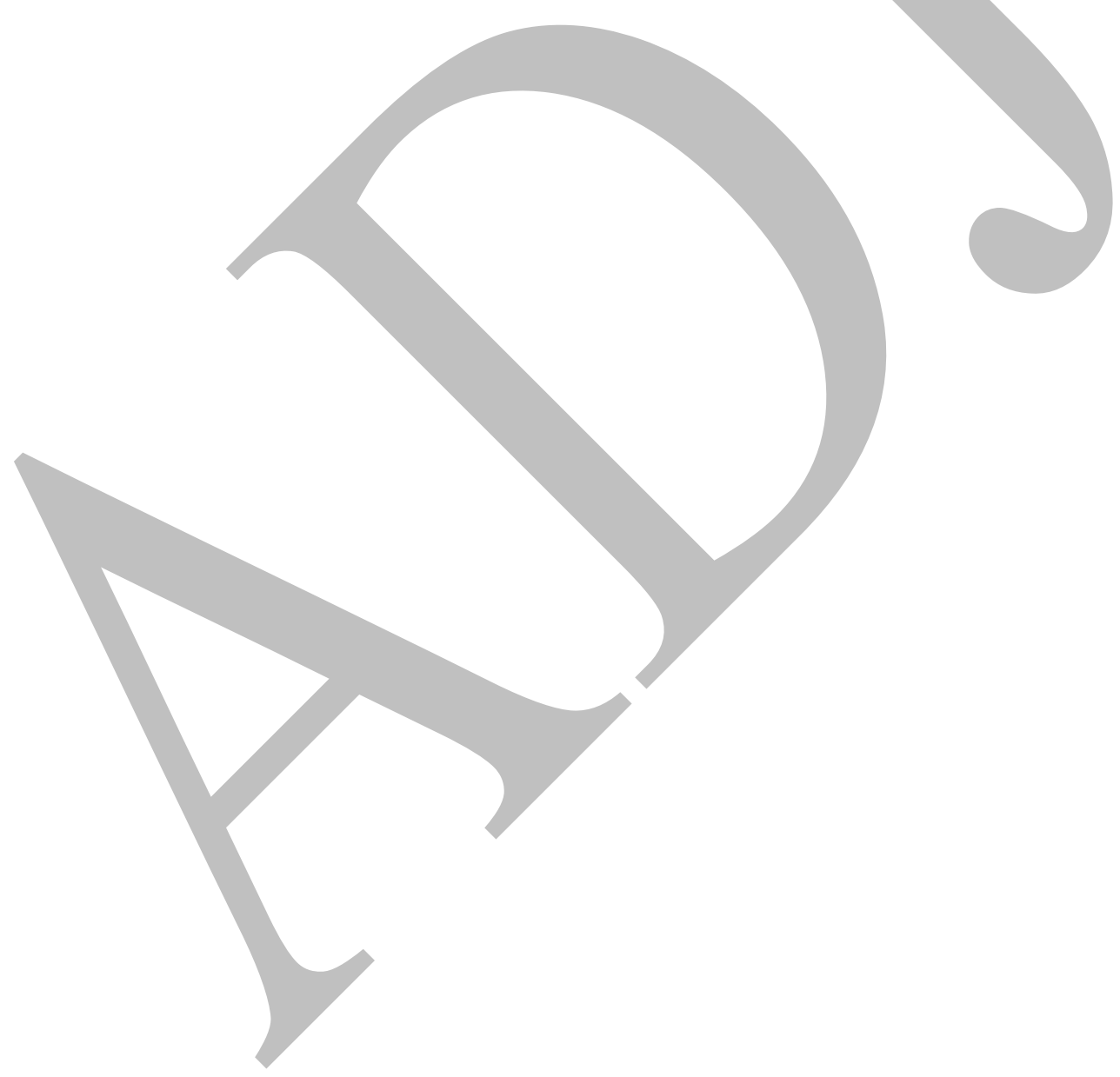

